\title{
Design and construction of a low cost single-supply embedded telemetry system for amperometric biosensor applications
}

\author{
Pier A. Serra ${ }^{\mathrm{a}, *}$, Gaia Rocchitta ${ }^{\mathrm{b}, \mathrm{c}}$, Gianfranco Bazzu ${ }^{\mathrm{a}}$, Antonio Manca ${ }^{\mathrm{a}}$, \\ Giulia M. Puggioni ${ }^{\mathrm{a}}$, John P. Lowry ${ }^{\mathrm{b}}$, Robert D. O'Neill ${ }^{\mathrm{c}}$ \\ ${ }^{a}$ Department of Pharmacology, Medical School, University of Sassari, Viale S. Pietro 43/b, 07100 Sassari, Italy \\ ${ }^{\mathrm{b}}$ UCD School of Biomolecular and Biomedical Sciences, University College Dublin, Belfield, Dublin 4, Ireland \\ ${ }^{\mathrm{c}}$ UCD School of Chemistry and Chemical Biology, University College Dublin, Belfield, Dublin 4, Ireland \\ Received 27 February 2006; accepted 11 May 2006 \\ Available online 27 June 2006
}

\begin{abstract}
A new embedded telemetry system for amperometric biosensor application is presented. The device consists of a single-supply miniature potentiostat- $I / V$ converter, a microcontroller unit (MCU), a signal transmitter, and a stabilized power supply. The sensor current is converted to a digital value using a peripheral interface controller (PIC) MCU with an integrated analog-to-digital converter (ADC). The PIC firmware is developed in assembly and transferred to the MCU through an in-circuit-serial-programmer (ICSP). The digital data are sent to a personal computer using a miniaturized $433.92 \mathrm{MHz}$ amplitude modulation (AM) transmitter with a linear range up to $30 \mathrm{~m}$. The radio receiver is connected to a PC via a Universal Serial Bus (USB). Custom developed software, written in C and Basic, allows the PC to record, plot and handle the received data. The design, construction and operation of the hardware and software are described. The system performance was evaluated in vitro using a dummy cell and a platinum $(\mathrm{Pt})$ amperometric glucose biosensor. This device serves as a basic model to realize an in vivo, low-cost, miniaturized telemetry system built with standard hardware components readily available.
\end{abstract}

(C) 2006 Elsevier B.V. All rights reserved.

Keywords: Potentiostat; Amperometry; Microcontroller; Biosensor; Telemetry

\section{Introduction}

A biosensor is defined as a device that combines a transducer with a biologically sensitive and selective component [1]. Many biologically oxidable molecules can be directly detected using amperometric sensors connected to an electronic device called a potentiostat [2]. When direct electrochemical oxidation is not possible under standard experimental conditions, a biosensor may then be used instead [3]. Glucose is oxidized by the enzyme glucose oxidase (GOx), an oxidoreductase with a covalently linked flavin adenine dinucleotide (FAD) cofactor [4]:

\section{$\beta$-d-glucose + FAD-oxidase}

$\rightarrow$ d-glucono- $\delta$-lactone $+\mathrm{FADH}_{2}$-oxidase

\footnotetext{
* Corresponding author. Tel.: +39079 228558; fax: +39079 228525 .

E-mail address: paserra@uniss.it (P.A. Serra).
}

The reconversion of $\mathrm{FADH}_{2}$ to $\mathrm{FAD}$ produces $\mathrm{H}_{2} \mathrm{O}_{2}$ in the presence of $\mathrm{O}_{2}$, as follows:

$\mathrm{FADH}_{2}$-oxidase $+\mathrm{O}_{2} \rightarrow$ FAD-oxidase $+\mathrm{H}_{2} \mathrm{O}_{2}$

The application of a potential of $+700 \mathrm{mV}$ to the Pt working electrode, relative to a reference electrode (e.g. $\mathrm{Ag} / \mathrm{AgCl}$ ), causes the following reaction:

$\mathrm{H}_{2} \mathrm{O}_{2} \rightarrow \mathrm{O}_{2}+2 \mathrm{H}^{+}+2 \mathrm{e}^{-}$

generating a measurable current that is proportional to the rate of the $\mathrm{H}_{2} \mathrm{O}_{2}$. The high specificity and stability of GOx makes this enzyme suitable for biosensor construction [5] when immobilized on the surface of platinum electrodes with poly- $O$ phenylenediamine [6].

Biomedical telemetry is a well established technique which allows real-time reading of glucose levels $[7,8]$ reducing distress in patients [9]. In recent years sophisticated telemetry systems have been developed to analyse neurochemical data, such as brain variations of dopamine, in freely moving animals $[10,11]$. 
In this paper we describe a MCU-based telemetry system, which can be used with biosensors for the measurement of brain glucose and other molecules in vitro and in vivo.

\section{Materials and methods}

\subsection{Reagents and solutions}

All chemicals were of analytical grade and used as supplied; MilliQ water was used throughout. The glucose oxidase (GOx) from Aspergillus Niger (EC 1.1.3.4.), $o$-phenylenediamine ( $o$ PD) and $\mathrm{D}(+)$-glucose were obtained from Sigma Chemicals (Milano, Italy). The stock solution of glucose $(1 \mathrm{M})$ was prepared in water and stored at room temperature for $24 \mathrm{~h}$ to allow the equilibration of the two anomers then used for calibration. The phosphate-buffer saline (PBS) solution was made using $\mathrm{NaCl}$ (137 mM), $\mathrm{KCl}(2.7 \mathrm{mM}), \mathrm{NaH}_{2} \mathrm{PO}_{4}(1.4 \mathrm{mM})$ and $\mathrm{Na}_{2} \mathrm{HPO}_{4}$ (4.3 mM) from Sigma, then adjusted to $\mathrm{pH}$ 7.4. The GOx solution was prepared dissolving 895 units $(5 \mathrm{mg})$ of enzyme in $50 \mu \mathrm{l}$ of PBS and then stored at $4{ }^{\circ} \mathrm{C}$. The $o$-PD monomer was dissolved in deoxygenated PBS immediately before the potentiostatic electrosynthesis of the polymer (poly-o-PD, PPD) on the Pt surface. The $3 \mathrm{M} \mathrm{NaOH}$ solution for the development of the positive photoresist was made in 11 of water dissolving $120 \mathrm{~g}$ of $\mathrm{NaOH}$ tablets (Sigma). The ferric chloride etching solution (2 M) was prepared dissolving $162.2 \mathrm{~g}$ of $\mathrm{FeCl}_{3}$ (Sigma) in $500 \mathrm{ml}$ of water.

\subsection{Materials and electronic parts}

Electronic parts were from RS Components Spa (Milano, Italy); the radio modules were from Telecontrolli spa (TC, Casoria, Italy), and the USB components preassembled by Elettronicamente (ELT, Milano, Italy). The power section of the transmitter unit was stabilized using a National LP2950-05 voltage regulator. The amperometric module of the transmitter unit was built using the National-LMC6064. The ADC was an integral part of the MCU used in this system (MicrochipPIC12F683). The 433.92 MHz AM transmitter with integrated antenna was a RT2-433.92 (TC). We selected a RR3-433.92 (TC) as AM receiver with external antenna. The serial-to-USB converter was a FTDI-FT232BM module (ELT) with a $6 \mathrm{MHz}$ quartz and a 93C46 E 2 PROM. All resistors were precision metal oxide thick film $(250 \mathrm{~mW}, 0.1 \%$ tolerance, Ohmite, Rolling Meadows, IL). All capacitors were NP0-type multilayer ceramic (low pass filter, decoupling) or electrolytic (decoupling). The components were soldered on a single side PCB board (eurocard size $-160 \mathrm{~mm} \times 100 \mathrm{~mm})$. Emilac $^{\circledR}$, Positiv ${ }^{\circledR}$ and Plastic ${ }^{\circledR}$ technical sprays were from Cramolin (Mühlacker, Germany).

\subsection{Transmitter unit circuit description}

The transmitter unit (Fig. 1) comprised four different modules. The amperometric module was built around the integrated circuit (IC) LMC6064, a quad single-supply operational amplifier (OPA). National Semiconductors designed this CMOS family of OPA for micropower applications with low input bias current (10 fA) and high input resistance $(>10 \mathrm{~T} \Omega)$. The
LMC6064 can operate from a single-supply voltage with "railto-rail" inputs and outputs. One OPA (Fig. 1a) serves as voltage follower connected to the wiper of $1 \mathrm{M} \Omega$ multiturn trimmer potentiometer. This circuit produces the voltage necessary to polarize the working electrode (WE) between 0 and $+1.25 \mathrm{~V}$ while the single OPA potentiostat (Fig. 1b) controls the reference (RE) and the auxiliary (AE) electrodes. The current-to-voltage $(I / V)$ converter (Fig. 1c) is a single-supply adaptation of a classic transimpedance amplifier [12] with a three-position adjustable gain varied by a rotary switch. The transfer function of the $I / V$ converter is:

$V_{\text {out } 1}=-\left(i_{\text {ox }} R_{\mathrm{f}}\right)+V_{\text {app }}$

where $i_{\mathrm{Ox}}$ is the oxidation current flowing through the WE, $R_{\mathrm{f}}$ is the feedback resistor and $V_{\mathrm{App}}$ is the potential applied to the WE. The resistors have capacitors in parallel to complete a low pass filter with a cut-off frequency ( $\left.F_{\text {cut-off }}\right)$ of $10 \mathrm{~Hz}$ for each range. The capacitor values $\left(C_{\mathrm{F}}\right)$ were calculated in Farads according to the equation:

$C_{\mathrm{F}}=1 /\left(F_{\text {cut-off }} 2 \pi R_{\mathrm{f}}\right)$

in which $R_{\mathrm{f}}$ is the resistor value for each range. The values of $C_{\mathrm{F}}$ are shown in Fig. 1c.

The difference amplifier circuit (Fig. 1d) has the dual role of subtracting the potential applied to the WE [12] while amplifying ten times the resulting signal. The transfer function of the differentiator is:

$V_{\text {out } 2}=\left(V_{\text {out } 1}-V_{\text {app }}\right)\left(R_{2} / R_{1}\right)+V_{\text {ref }}\left(R_{2} / R_{1}\right)$

where: $V_{\text {out1 }}$ and $V_{\text {app }}$ are the signals applied to the inputs and the values of $R_{1}$ and $R_{2}$ are respectively 1 and $10 \mathrm{M} \Omega$. $V_{\text {ref }}$ is equal to $0 \mathrm{~V}$ because the $10 \mathrm{M} \Omega$ resistor is grounded, then:

$V_{\text {out2 }}=10\left(V_{\text {out } 1}-V_{\text {app }}\right)$

The combination of the two stages of amplification (Fig. 1c and d) provides three different full scales, ranging from $1 \mathrm{nA} / \mathrm{V}$ $(100 \mathrm{M} \Omega)$ up to $100 \mathrm{nA} / \mathrm{V}(1 \mathrm{M} \Omega)$, with the global transfer function:

$V_{\text {out }}=-10\left(i_{\mathrm{ox}} R_{\mathrm{f}}\right)$

The low tolerance resistors $(0.1 \%)$ reduce the error in the $I / V$ and differentiator circuits. With a power supply of $+5 \mathrm{~V}$ the maximum input current is almost $500 \mathrm{nA}$ (494 nA in the observed "rail-to-rail" output). In this range of amplifications it is possible to calibrate accurately a glucose biosensor (Pt disk, $125 \mu \mathrm{m}$ diameter) in vitro.

The power supply module (Fig. 1e) was constructed using a LP2950-5.0, +5 V voltage regulator, and two decoupling capacitors. This IC has very low quiescent current $(75 \mu \mathrm{A})$, low drop-out voltage $(40-100 \mathrm{mV})$ and excellent linear regulation $(0.05 \%)$.

The PIC12F683 is the heart of the digital module (Fig. 1f). This is a 8-bit CMOS IC with low power features equipped with an internal variable clock ( $31 \mathrm{KHz}-8 \mathrm{MHz}$, software selectable) and a 10 bit ADC with four multiplexed channels. The MCU, working at $4 \mathrm{MHz}$, performed the ratiometric $\mathrm{A} / \mathrm{D}$ conversion 


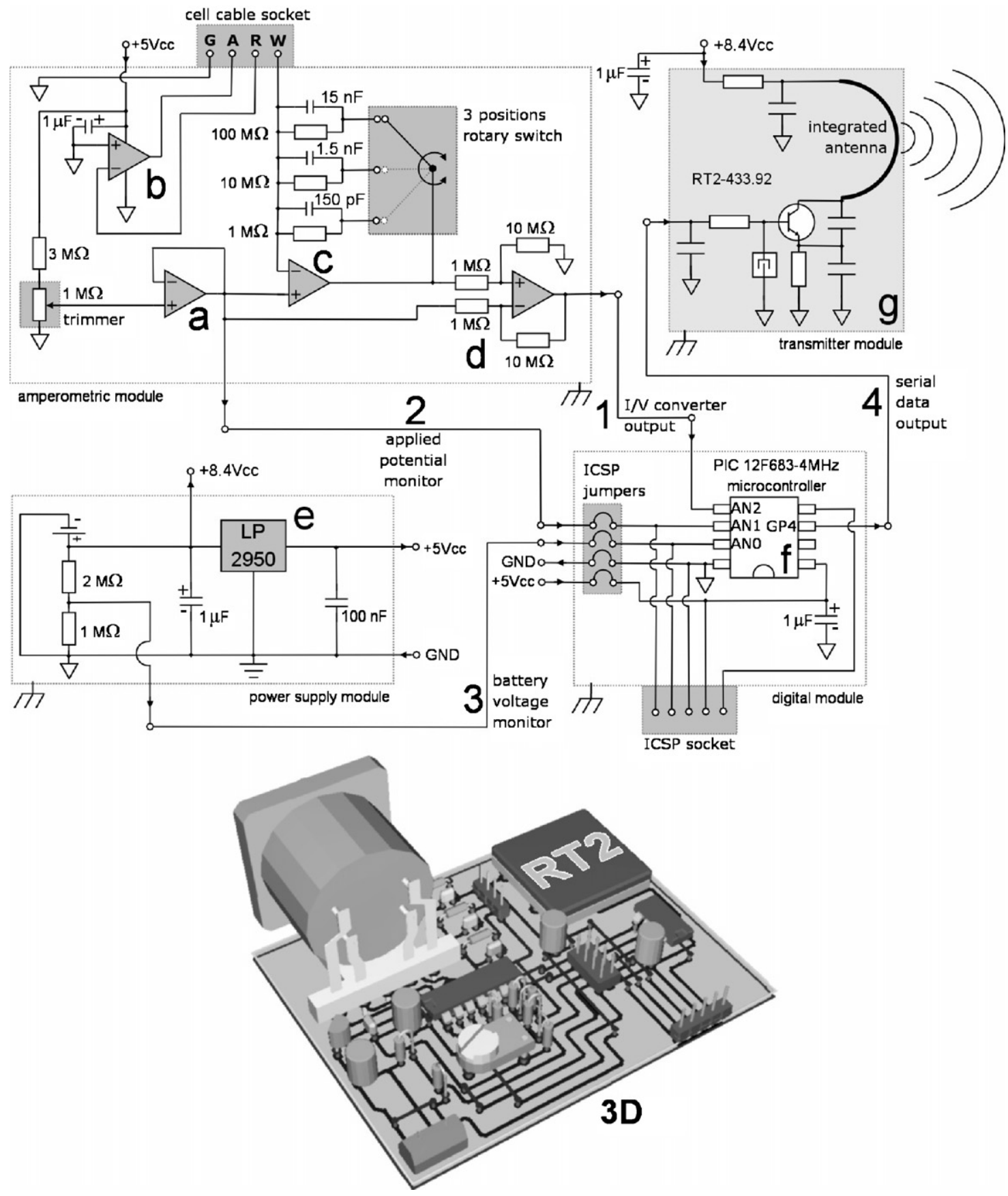

Fig. 1. Circuit diagram and three dimensional representation (3D) of the transmitter unit. The amperometric module comprised a buffered voltage follower (a), a single OPA potentiostat (b), a current-to-voltage converter (c) and a single supply differentiator/amplifier (d). The $+5 \mathrm{~V}_{\mathrm{cc}}$ voltage was stabilized by the power supply module equipped with a low drop out voltage regulator (e). The in-circuit programmable digital module (f) was equipped with a PIC-12F683 MCU connected to three analog lines: $I / V$ converter output (1), applied voltage monitor (2) and battery voltage monitor (3). The serial data output (4) from the MCU was directly connected to the input pin of the transmitter module $(\mathrm{g})$.

of $V_{\text {out }}$ (Fig. 1 1-3), $V_{\text {app }}$ and battery voltage $\left(V_{\text {batt }}\right)$. After the digital signal processing (DSP) of acquired raw data, a serial data packet was generated and sent to the transmitter (Fig. 1 4). The in-circuit-serial-programming (ICSP) bus provides the possibility of programming the IC "on-board" in a few seconds.

The miniaturized transmitter $(17.8 \mathrm{~mm} \times 10.16 \mathrm{~mm}$; Fig. $1 \mathrm{~g})$ is a thick film AM module, with SAW controlled oscillator and integrated antenna, running at the frequency of $433.92 \mathrm{MHz}$. In conjunction with the MCU, this hybrid component allows the realization of a serial data transmitter working at the maximum speed of 2400 baud.

A rechargeable $8.4 \mathrm{~V}$ Nickel-Metal hydride (Ni-Mh) Battery pack $(3300 \mathrm{~mA} / \mathrm{h})$ provided the power to the transmitter unit.

\subsection{Receiver unit circuit description}

The receiver unit (Fig. 2) comprises two parts: the receiver module (Fig. 2a) and the serial-to-USB converter (Fig. 2b). The 


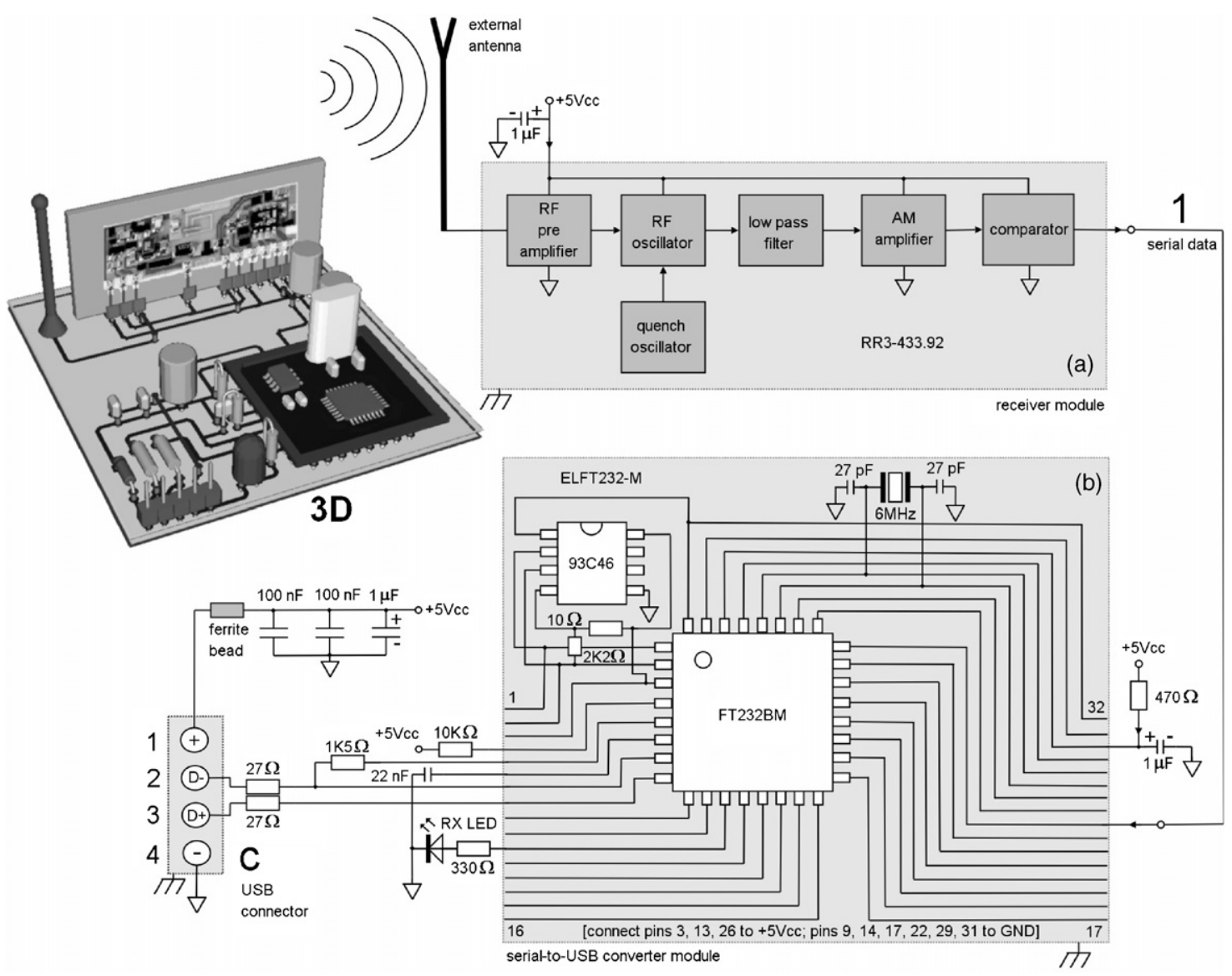

Fig. 2. Receiver unit: three dimensional representation (3D) and circuit diagram. The AM signal was decoded by the receiver unit (a) connected to a $17.28 \mathrm{~cm}$ "whip" antenna. The serial data (1) was sent to the serial-to-USB converter (b) and transmitted to the personal computer (c). The unit was powered by the USB bus without the necessity of using an external power supply.

RR3-433.92 receiver $(\mathrm{RX})$ is a super regenerative data receiver with a high frequency accuracy conferred by virtue of a laser trimmed inductor. An external "whip" antenna, consisting of one quarter of wavelength $(\lambda / 4)$ straight wire, was connected directly to the antenna pin of the RX. The length of the wire was calculated in centimetres from the following formula:

$L_{\mathrm{cm}}=7500 /$ frequency $_{\mathrm{MHz}}$

At $433.92 \mathrm{MHz}, L_{\mathrm{cm}}$ is equal to 17.28 . The $\mathrm{RX}$ module sent the digital serial data (Fig. 21 ) to the Serial-to-USB converter. This module was built around the FT232BM, clocked at $6 \mathrm{MHz}$ and connected to an external 93C46 E 2 PROM (used to store USB ID parameters, resource configuration, etc.). A LED provided direct visualization of received packets. A few resistors and decoupling capacitors completed the USB interface and the $+5 \mathrm{~V}$ power supply, derived from the USB.

\subsection{PCB design and construction}

The components placement was simulated using a graphic software (KiCAD). The three-dimensional (3D) reconstructions of the transmitter and receiver units are illustrated in Fig. 1, 3D and Fig. 2, 3D.
The printed circuit board (PCB) tracks were designed with a freely available software (KBan 2.0) and printed on a transparency using a HP Laserjet 1200. The PCB board was cleaned with sandpaper (3 M, Microfine-1500 grit) and rinsed with water and acetone before applying a coating of positive photoresist (Positiv ${ }^{\circledR}$ ). After 45 min the board was coupled with the printed transparency, using removable tape, and exposed to direct UV light for $5 \mathrm{~min}$. The PCB was then immersed in the development solution for a few minutes and etched in $\mathrm{FeCl}_{3}$ bath for $15 \mathrm{~min}$ at $40{ }^{\circ} \mathrm{C}$. After inspection, and photoresist cleaning using sandpaper and acetone, the through-holes $(\varnothing=0.6 \mathrm{~mm})$ were drilled and the two units were separated using a snap-off knife. The electronic components were soldered with a low power solder iron $\left(12 \mathrm{~W}\right.$, Weller, Germany) and an insulating coating (Plastic ${ }^{\circledR}$ ) was applied to the copper side of the boards. The final size of the transmitter and the receiver boards was $60 \mathrm{~mm} \times 80 \mathrm{~mm}$ and $160 \mathrm{~mm} \times 80 \mathrm{~mm}$, respectively. At the end, the units were put in small plastic envelopes pre-treated with copper-based antistatic spray $\left(\operatorname{Emilac}^{\circledR}\right)$ to minimize electromagnetic interferences (EMI).

\subsection{Electrochemical cell}

The three electrode cell for biosensor electropolymerisation and calibration was home made and the schematic is shown 

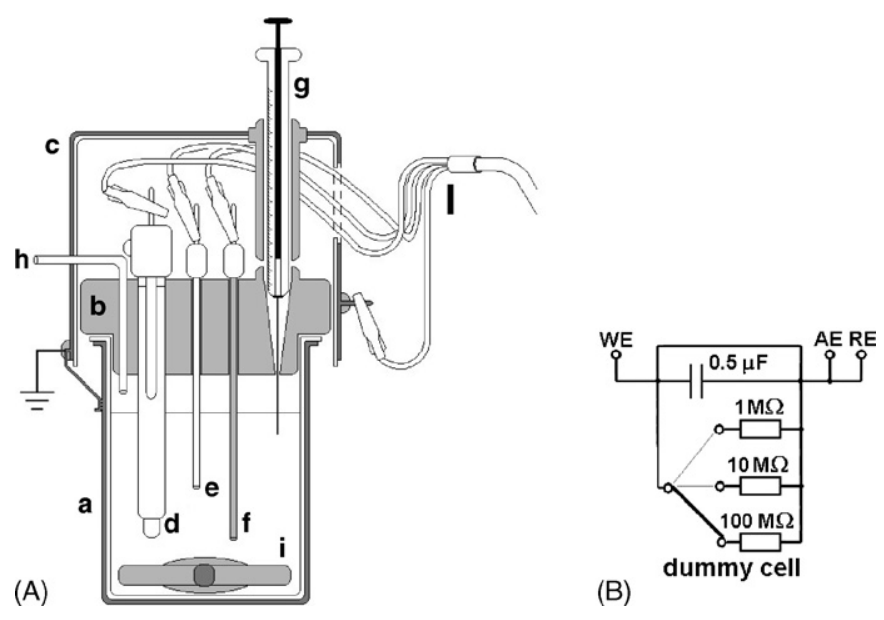

Fig. 3. Schematic representation (A) of the electrochemical cell used for electropolymerisation and for testing the telemetry system with a glucose biosensor; (a) $25 \mathrm{ml}$ PTFE beaker externally coated with antistatic spray (see text); (b) drilled Teflon ${ }^{\odot}$ top; (c) antistatic cup enclosing the various electrode connectors (see text); (d) $\mathrm{Ag} / \mathrm{AgCl}$ reference electrode; (e) working electrode/glucose biosensor; (f) platinum auxiliary electrode; (g) Hamilton injection syringe used for glucose calibration; (h) nitrogen/air inlet tube; (i) magnetic stirrer bar; (l) cell cable. A dummy cell (B) was used for testing the amperometric module of the transmitter unit before the biosensor calibration.

in Fig. 3 (panel A). It comprises a $25 \mathrm{ml}$ PTFE beaker $(\mathrm{H}$ : $45 \mathrm{~mm} \times$ diam.: $33 \mathrm{~mm}$, Plastibrand, Milano, Italy) sealed with a Teflon ${ }^{\odot}$ lid $(\varnothing=32 \mathrm{~mm})$ with five holes drilled into it to insert the electrodes, the nitrogen/air tube and the syringe needle. The external surface of the beaker was treated with antistatic spray $\left(\mathrm{Emilac}^{\odot}\right)$ and connected to the ground of the transmitter unit and to the earth ground. An antistatic cup, enclosing the various electrode connectors (crocodile clips), was constructed by cutting a $50 \mathrm{ml}$ PTFE beaker (H: $30 \mathrm{~mm} \times$ diam.: $45 \mathrm{~mm}$, Plastibrand) externally sprayed with Emilac ${ }^{\odot}$. Electrical continuity between the cup and the beaker was consistently achieved through a small copper plaque glued to the cup with epoxy before the antistatic treatment. The conducting surface formed a Faraday cage to reduce EMI. For the duration of the electrosynthesis, nitrogen was introduced into the cell to prevent oxygen interference. During the calibration procedure with glucose the cell was placed on the stirrer and a $32 \mathrm{~mm}$ diameter magnetic bar was used to mix the solution after each addition of glucose. A dummy cell was made as shown in Fig. 3 (panel B) for testing the amperometric module of the transmitter unit before the biosensor calibration.

\subsection{Glucose biosensor preparation and calibration}

Poly-o-PD-based glucose biosensors were prepared modifying a protocol described by Lowry and co-workers [6]. This biosensor design has been successfully used to quantify ECF striatal brain glucose $(\sim 400 \mu \mathrm{M})$ in freely moving rats [13]. In brief $40 \mathrm{~mm}$ length Teflon $^{\circledR}{ }^{-}$-coated platinum/iridium (90\%/10\%) wire (5T-125 $\mu \mathrm{m}$ diameter, Advent Research Materials, Suffolk, UK) was soldered to a gold pin (RS Components) after carefully cutting $2 \mathrm{~mm}$ of the Teflon ${ }^{\circledR}$ insulation. The other end of the wire was cut with a scalpel blade to expose the $1 \mathrm{~mm}$ platinum cylinder and rinsed with bidistilled water. The sensor was immersed in the GOx solution for 5 min to ensure adequate enzyme adsorption. After $10 \mathrm{~min}$ drying at room temperature the biosensor was placed in the cell filled with $5 \mathrm{ml}$ of nitrogenated PBS containing the $o$-phenylenediamine monomer in nitrogen atmosphere. The reference and auxiliary electrodes were respectively an $\mathrm{Ag} / \mathrm{AgCl}$ electrode and a $50 \mathrm{~mm}$ platinum wire (BAS-Bioanalytical Systems Inc., West Lafayette, US). The cell was connected to a CV37 voltammograph (BAS) and the electropolymerisation process started by applying a $+700 \mathrm{mV}$ potential to the WE versus RE. The gain of the CV37 was fixed to $500 \mathrm{nA} / \mathrm{V}$ to prevent the saturation of the input stage. After $20 \mathrm{~min}$ the potential was disconnected and the glucose biosensor was rinsed with bidistilled water and stored at $4{ }^{\circ} \mathrm{C}$ overnight. The in vitro calibration was carried out the following day at room temperature. The glucose biosensor was placed in the cell containing $15 \mathrm{ml}$ of air-bubbled PBS (Fig. 3). A +700 mV potential was applied and the current recorded until a stable baseline was obtained. Ten successive injections of glucose $(1 \mathrm{M}$ stock solution) were performed and a calibration curve in the range of concentrations between 0.2 and $140 \mathrm{mM}$ was obtained (Fig. 5).

\subsection{Firmware and software}

The firmware to drive the PIC12F683 was realized in assembly language using MPLab, the Microchip integrated development environment, freely available from http://www. microchip.com. The program, which runs on the MCU, consists of a main routine that is divided in two portions of code. The first portion initializes the communications port and all the other modules of the PIC (ADC and timers in particular). The second portion is an infinite loop that performs the ADC conversions, calculates the 8 Bit Cyclic Redundancy Check (CRC) and sends data through the serial port. The analogue signals $V_{\text {out }}$, $V_{\text {app }}$ and $V_{\text {bat }}$ are multiplexed, digitized with a sample period of $2 \mu \mathrm{s}$, and sent to the transmitter module. Only for the $V_{\text {out }}$ signal, the hardware ADC resolution (10 bit) was improved following the oversampling and averaging method [14]:

$F_{\mathrm{os}}=4^{w} F_{\mathrm{s}}$

where $w$ is the number of additional bits of resolution (4), $F_{\mathrm{s}}$ is the sampling frequency $(20 \mathrm{~Hz})$ and $F_{\mathrm{os}}$ is the oversampling frequency $(5120 \mathrm{~Hz})$. In accordance with the Nyquist's theorem $F_{\mathrm{S}}$ was calculated as follows:

$F_{\mathrm{s}}=2 F_{\max }$

where $F_{\max }$ is equal to $10 \mathrm{~Hz}$, the highest frequency of the input signal. To do that, the PIC acquired and accumulated 256 consecutive samples in $50 \mathrm{~ms}$ then right-shifted the sum by one bit (divided by 2). This technique increased the ADC resolution from 10 to 14 bits. The seven byte packets ( 20 per second), sent by the MCU, were composed as follows: the "head" byte (synchronization), the value of $V_{\text {out }}$ ( 2 bytes), the 8-lowersignificant-bits (8-LSB) of the $V_{\text {app }}$ and $V_{\text {batt }}$ (8-LSB). The CRC 
value of the previous four bytes and the "tail" synchronization byte completed the sequence.

The compiled file was downloaded to the MCU using the Microchip USB programmer (PICkit ${ }^{\circledR}$ ) connected to the ICSP bus.

The software, running on the PC under Windows XP Professional, was interfaced to the USB receiver unit by using the low-level driver freely available from http://www.ftdichip.com. The graphic user interface was developed in RealBasic 2006 while the dynamic link library (DLL) serial-data-parser was programmed in $\mathrm{C}$ (Dev-C $\mathrm{C}^{++}$4.9). The application is capable of plotting, storing and retrieving data. A software alarm was generated when the calculated CRC differed from the transmitted value, a data reception time-out occurred or the battery level in the transmitter unit was too low $(<7.2 \mathrm{~V})$.

\section{Results}

\subsection{Electronics test and calibration}

The dummy cell previously described (Fig. 3B) was used as a Thevenin current source connected to the amperometric module. The voltage applied to the dummy cell was generated between the WE and the AE/RE electrodes and is equal to the voltage applied to the WE:

$i_{\text {dummy }}=V_{\text {app }} / R_{\text {dummy }}$

The resulting anodic current $\left(i_{\text {dummy }}\right)$ was read by the WE and converted in the resulting voltage (Eq. (5), $\left.V_{\text {out }}\right)$ by the amperometric module.

The calibration was made indoors with a linear distance between the TX RX units of $\sim 10 \mathrm{~m}$. The baseline was recorded for six consecutive days of continuous operation and a 10point calibration was performed daily $(n=6)$ for each amplification range. The logarithmic plot in Fig. 4 (panel A) represents the calibration currents for each amplification decade: $100 \mathrm{M} \Omega \quad$ (slope $\left.=0.00991 \pm 0.00007 \mathrm{nA} \mathrm{mV}^{-1} ; r^{2}=0.9996\right)$, $10 \mathrm{M} \Omega$ (slope $\left.=0.09931 \pm 0.00046 \mathrm{nA} \mathrm{mV}^{-1} ; r^{2}=0.9998\right)$ and $1 \mathrm{M} \Omega\left(\right.$ slope $\left.=0.9931 \pm 0.0048 \mathrm{nA} \mathrm{mV}^{-1} ; r^{2}=0.9998\right)$. From the same plot it is possible to extrapolate the values of $R_{\text {dummy }}$ and $V_{\text {app }}$ used for calibrating. A second calibration was made under the same conditions, connecting the $V_{\text {out }}$ of the amperometric module to a Fluke 45 Voltmeter. No significant statistical differences were observed between the two calibrations (data not shown). After the operations described above, a $2.5 \mathrm{nA}$ current was generated though the dummy cell, setting the $R_{\text {dummy }}$ and the $I / V$ resistors to $100 \mathrm{M} \Omega$ and fixing $V_{\text {app }}$ to $+250 \mathrm{mV}$. The system was left under these conditions up to the next calibration, which was made the following day. A maximum $V_{\text {app }}$ shift of $10 \mathrm{mV}$ was observed overnight while the current of the baseline noise was around $10 \mathrm{pA}$ (Fig. 4, panel B).

At the end of the calibrations, all the values of the recorded current were plotted versus the expected current values, producing a 30-point graph (slope $=0.9954 \pm 0.0022 \mathrm{nAnA}^{-1}$; $r^{2}=0.9999 ; n=6$ ) comprehensive of the full amplification range (Fig. 4, panel C).
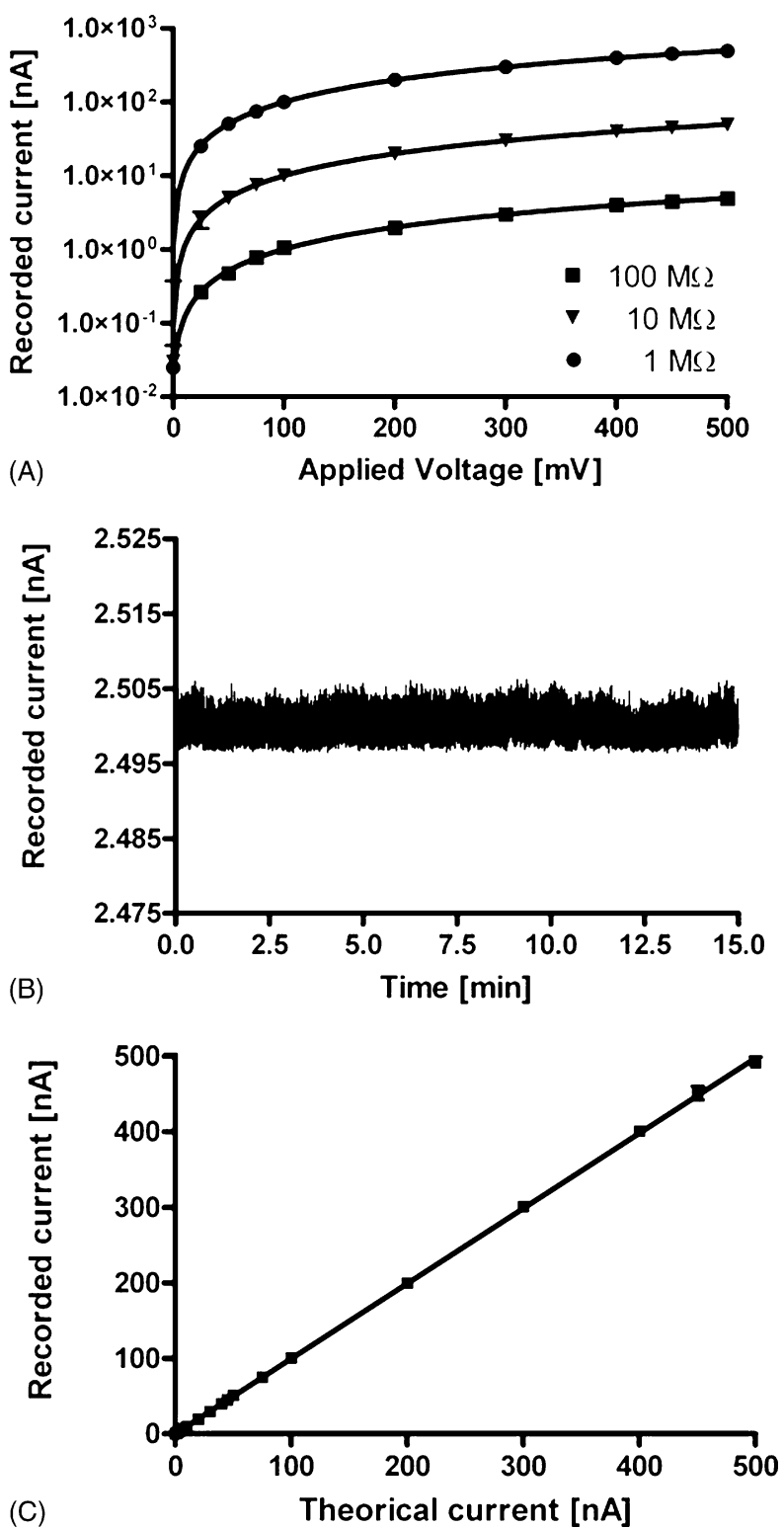

Fig. 4. Calibration of the transmitter unit by connecting the dummy cell and using it as a Thevenin current source (see text). The baseline was recorded for six consecutive days of continuous operation and a 10 points calibration was performed daily $(n=6)$ for each amplification range. The logarithmic plot in panel A represents the calibration currents: $100 \Omega$ (slope $=0.00991 \pm$ $\left.0.00007 \mathrm{nA} \mathrm{mV}^{-1} ; r^{2}=0.9996\right), 10 \mathrm{M} \Omega\left(\right.$ slope $=0.09931 \pm 0.00046 \mathrm{nA} \mathrm{mV}^{-1}$; $\left.r^{2}=0.9998\right)$ and $1 \mathrm{M} \Omega$ (slope $\left.=0.9931 \pm 0.0048 \mathrm{nA} \mathrm{mV}^{-1} ; r^{2}=0.9998\right)$. The noise was quantified around $10 \mathrm{pA}$ (panel B) setting the dummy cell and the $I / V$ resistors to $100 \mathrm{M} \Omega$ and applying $+250 \mathrm{mV}$ to the $\mathrm{WE}$. The values of the recorded current were then plotted vs. the expected current values generating a 30 points calibration graph (slope $=0.9954 \pm 0.0022 \mathrm{nA} \mathrm{nA}^{-1} ; r^{2}=0.9999$; panel C) comprehensive of the full amplification range.

\subsection{Power consumption}

The total current necessary to drive the transmitter unit, powered with $\mathrm{a}+8.4 \mathrm{~V} \mathrm{Ni-Mh}$ battery, was experimentally determined [15] as $8.5 \mathrm{~mA}$. The calculated power consumption was $71.4 \mathrm{~mW}$. After the insulation of the modules we tested the partial power consumptions determining the subcircuit currents using an external power supply (TP3005D-3, TekPower ${ }^{\circledR}$, 
US) and a precision microammeter (Fluke 45, Fluke, US). The power supply module without load had a quiescent current of $78 \mu \mathrm{A}(655 \mu \mathrm{W})$. The amperometric + digital modules $(+5 \mathrm{~V})$ consumed $27 \mathrm{~mW}$, and the transmitter module $25 \mathrm{~mW}(+8.4 \mathrm{~V})$. In order to reduce the power consumption we decreased the supply voltage of the transmitter module down to $+5 \mathrm{~V}$ without effects on the transmitter performance. Because the power consumption of the receiver unit is less critical, we checked only the total current necessary to drive the unit $(45 \mathrm{~mA}, 225 \mathrm{~mW})$.

\subsection{Biosensor response to glucose}

The in vitro response to glucose (Fig. 5) of PPD-based biosensors $(n=4)$ in the range between 0 and $140 \mathrm{mM}$ showed classical Michaelis-Menten kinetics $\left(r^{2}=0.989\right)$. The values of $V_{\max }$ and $K_{\mathrm{m}}$, expressed as mean $\pm \mathrm{SEM}$, were respectively $82 \pm 2 \mathrm{nA}$ and $4.2 \pm 0.4 \mathrm{mM}$. The response to low concentrations of glucose $(0-2 \mathrm{mM})$ revealed a good linearity $\left(r^{2}=0.991\right)$ with a slope of $13.5 \pm 0.8 \mathrm{nA} \mathrm{mM}^{-1}$. After the calibration of each biosensor connected to the telemetry system, the calibration (of the same
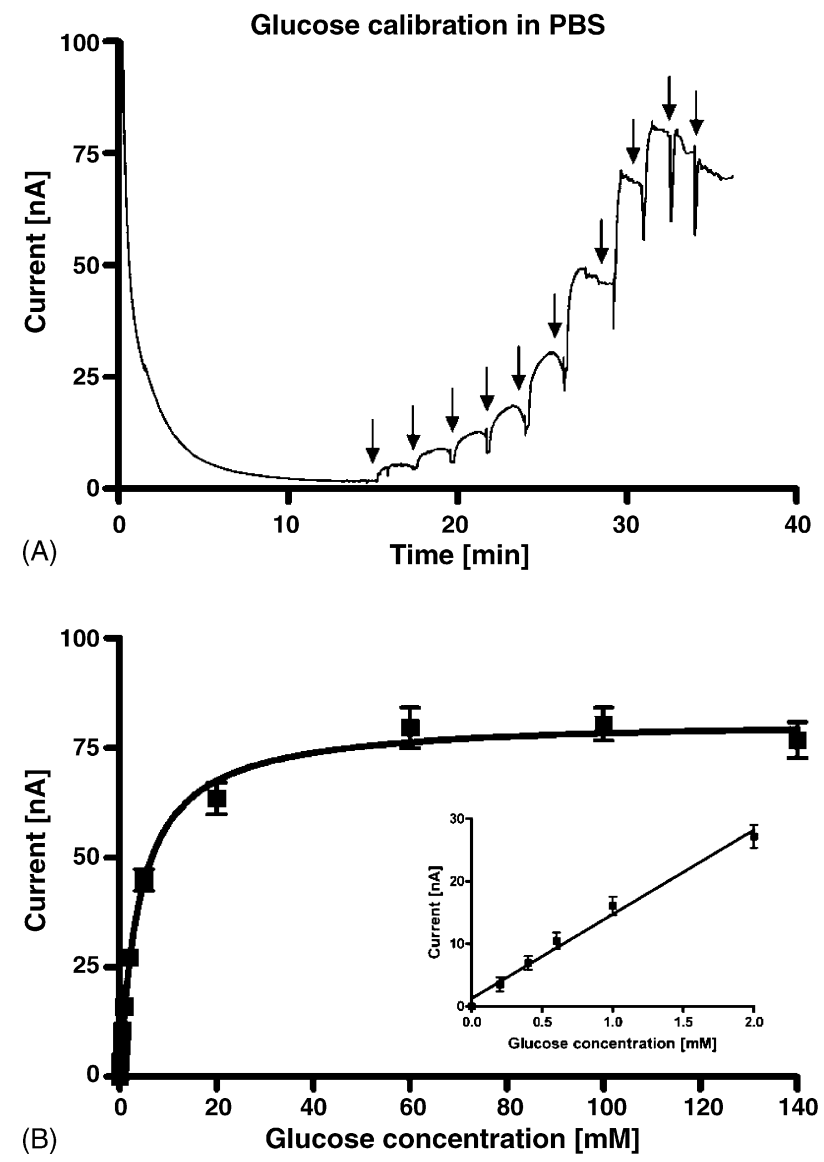

Fig. 5. In vitro response to glucose (0-140 mM) of PPD-based glucose biosensors $(n=4)$ connected to the transmitter unit. Ten successive injections of glucose (panel A) were made, using the three electrode cell illustrated in Fig. 3, after the stabilization in PBS at room temperature $\left(25^{\circ} \mathrm{C}\right)$. The calibration $(0.2,0.4,0.6,1,2,10,20,60,100,140 \mathrm{mM})$ showed classical MichaelisMenten kinetics $\left(r^{2}=0.9885\right)$ with a $V_{\max }$ of $81.65 \pm 1.61 \mathrm{nA}$ and a $K_{\mathrm{m}}$ of $4.193 \pm 0.383 \mathrm{mM}$ (panel B). The response to low concentrations of glucose $\left(0-2 \mathrm{mM}\right.$; panel B, small graph) revealed good linearity $\left(r^{2}=0.9913\right)$ with a slope of $13.48 \pm 0.76 \mathrm{nA} \mathrm{mM}^{-1}$. sensor) was repeated using a BAS CV-37 potentiostat. No statistical differences were observed between the two calibrations (data not shown).

\section{Discussion}

\subsection{Principles of operation and performance of the amperometric module}

The amperometric module circuit was optimized for singlesupply, low-voltage operation, through the distributing of the gain between the $I / V$ converter and the differentiator. In this way a maximum voltage output of $500 \mathrm{mV}$ from the first stage of amplification, with a theorical $V_{\text {app }}$ span from 0 to $4.5 \mathrm{~V}$, was achieved without the saturation of the second stage. The "railto-rail" output of the differentiator circuit $\left(V_{\text {out }}\right)$ corresponds to 10 times the $V_{\text {app }}$-subtracted current signal. $V_{\text {out }}$ is comprised between 0 and $+4.94 \mathrm{~V}$. The limitations of this design are related to variations of the resistor values, mainly in the difference circuit. The choice of low tolerance $(0.1 \%)$ components minimized such limitations. In fact, the module is characterized by high stability, low noise (Fig. 4A) and good linear response (Fig. 4B and $\mathrm{C}$ ). The system can operate only in oxidation mode and it is particularly suited to work in conjunction with oxidase-based biosensors and direct $\mathrm{H}_{2} \mathrm{O}_{2}$ detection [6] as illustrated in Fig. 5 . An alternative oxidation/reduction configuration is possible connecting the differentiator $V_{\text {ref }}$ (Eq. (3)) to $2.5 \mathrm{~V}$ and substituting the $10 \mathrm{M} \Omega$ with $1 \mathrm{M} \Omega$ resistors $\left(R_{2}\right)$. In this case $V_{\text {app }}$ becomes $2.5 V \pm V_{\text {app }}$ but the system loses all the advantages previously described.

\subsection{Digital module and data transmission}

The MCU, present in the transmitter unit, serves as ADC, DSP and serial transmitter. In conjunction with the AM module, a complete digital wireless system has been implemented and the CRC calculation guarantees an optimal error check. The low pin number, internal ADC and the built-in oscillator make this component ideal for embedded applications.

All experiments were made indoors and no communication problems were observed modifying the transmission distance in a linear range between 0 and $15 \mathrm{~m}$.

The low transmission speed may prove to be a disadvantage for real-time applications. However, the $20 \mathrm{~Hz}$ sample rate is sufficient to detect sub-second variations of oxidation current compared with previous studies [9-11]. In addition, the MCU DSP improves the system performance. Experiments are in progress using frequency modulation (FM) modules to obtain an increase in the serial data stream up to $9600 \mathrm{bps}$.

The receiver unit was interfaced to the software via USB with the possibility of high-level access to the received packets. This means simple data capture and handling with popular software packages such as LabView ${ }^{\circledR}$ or Dasylab ${ }^{\circledR}$.

\subsection{Miniaturization and future applications}

The system developed in this paper is similar to that previously described by Yun and colleagues (2004) [16]. Yun illus- 
trated a miniaturized wireless device for amperometric environmental monitoring with a built-in FM transmitter. In the present study we propose a system based on discrete components and pre-built critical modules (TX, RX, USB-transceiver), available at low cost, so no complex hardware calibrations are needed. The CMOS technology allows one to decrease the operating voltage and the power consumption. Studies are in progress to develop a miniaturized TX unit using surface mount (SM) components and a single $+3 \mathrm{~V}$ lithium cell. The reduction of the size and the weight of the transmitter unit should permit its use in in vivo applications as a lightweight portable/implantable device. The in vitro characteristics of the proposed system justifies further studies in order to monitor glucose levels in the brain of freely moving animals, but also other molecules present in the extracellular brain compartment such as lactate, ascorbic acid and nitric oxide.

\section{Conclusion}

In this paper we have described a new complete telemetry system for biosensor applications. Although based on simple and inexpensive components, the transmitter and the receiver devices can be used for accurate transduction of the anodic oxidation current generated on the surface of a biosensor. At this stage of the development process the system exhibits high stability, low noise and good linear response in the nanoampere current range. The choice of low power CMOS technology makes the project suitable of further improvements such as the reduction of the operating voltage and the power consumption. The use of SM components and careful PCB design will make it possible to miniaturize the circuitry and to assemble a transmitter unit suitable for in vivo applications with freely moving animals.

\section{Acknowledgements}

The authors acknowledge the Italian distributors of Microchip and National corporations for free samples of integrated circuits and Telecontrolli s.p.a. for the kind gift of miniaturized transmitters. The research was supported by University of Sassari (ex $60 \%$ fund). We also acknowledge support from Science Foundation Ireland (SFI; 03/IN3/B376).

\section{References}

[1] F.W. Scheller, F. Schubert, J. Fedowitz, Frontiers in Biosensorics I Fundamental Aspects, Birkhauser Verlag, Basel, 1997.

[2] A.J. Bard, L.R. Faulkner, Electrochemical Methods: Fundamentals and Applications, John Wiley \& Sons, New York, 1980.

[3] P. Pantano, W.G. Kuhr, Enzyme-modified microelectrodes for in vivo neurochemical measurements, Electroanalysis 7 (1995) 405.

[4] D. Pfeiffer, F. Schubert, U. Wollenberger, F.W. Scheller, Electrochemical sensors: enzyme electrodes and field effect transistors, in: R.F. Taylor, J.S. Schultz (Eds.), Handbook of Chemical and Biological Sensors, IOP, England, 1996, pp. 435-458.

[5] R. Wilson, A.P.F. Turner, Glucose oxidase: an ideal enzyme, Biosens. Bioelectron. 7 (1992) 165-185.

[6] J.P. Lowry, M. Miele, R.D. O'Neill, M.G. Boutelle, M. Fillenz, An amperometric glucose-oxidase/poly (o-phenylenediamine) biosensor for monitoring brain extracellular glucose: in vivo characterisation in the stria- tum of freely-moving rats, J. Neurosci. Methods 79 (1) (1998) 6574 .

[7] D.C. Leuher, Overview of biomedical telemetry techniques, Eng. Med. Biol. 3 (1983) 17-24.

[8] M. Shichiri, N. Asasawa, Y. Yamasaki, R. Kawamori, H. Abe, Telemetry glucose monitoring device with needle glucose sensor: a useful tool for blood glucose monitoring in diabetic individuals, Diabetes Care 9 (1986) 298-301.

[9] J. Black, M. Wilkins, P. Atanasov, E. Wilkins, Integrated sensor-telemetry system for in vivo glucose monitoring., Sens. Actuators B: Chem. 31 (1996) 147-153.

[10] F. Crespi, D. D’alessandro, V. Annovazzi-Lodi, C. Heidbreder, M. Norgia, In vivo voltammetry: from wire to wireless measurements, J. Neurosci. Methods 140 (1-2) (2004) 153-161.

[11] P.A. Garris, R. Ensman, J. Poehlman, A. Alexander, P.E. Langley, S.G. Sandberg, P.G. Greco, R.M. Wightman, G.V. Rebec, Wireless transmission of fast-scan cyclic voltammetry at a carbon-fiber microelectrode: proof of principle, J. Neurosci. Methods 140 (1-2) (2004) 103-115.

[12] J. Millar, J.J. O'Connor, S.J. Trout, Z.L. Kruk, Continuous scan cyclic voltammetry (CSCV): a new high-speed electrochemical method for monitoring neuronal dopamine release, J. Neurosci. Methods 43 (1992) $109-118$.

[13] J.P. Lowry, R.D. O'Neill, M.G. Boutelle, M. Fillenz, Continuous monitoring of extracellular glucose concentrations in the striatum of freely moving rats with an implanted glucose biosensor, J. Neurochem. 70 (1) (1998) 391-396.

[14] G. Pagnacco, E. Oggero, D.R. Morr, N. Berme, Oversampling data acquisition to improve resolution of digitized signals, Biomed. Sci. Instrum. 34 (1997) 137-142

[15] M.D. Steinberg, C.R. Lowe, A micropower amperometric potentiostat, Sens. Actuators B: Chem. 97 (2004) 284-289.

[16] K.S. Yun, J. Gil, J. Kim, H.J. Kim, K. Kim, D. Park, M.S. Kim, H. Shin, K. Lee, J. Kwak, E. Yoon, A miniaturized low-power wireless remote environmental monitoring system based on electrochemical analysis, Sens. Actuators B: Chem. 102 (1) (2004) 27-34.

\section{Biographies}

Pier Andrea Serra is professor of Pharmacology at University of Sassari, Medical School. He received his degree as Medical Doctor at Sassari University in 1998. He studied the in vivo Neurochemistry of Parkinson's Disease using microdialysis and voltammetry under the supervision of Dr. Maddalena Miele and received his $\mathrm{PhD}$ in Pharmacology and Toxicology from Sassari University in 2001. He worked as a Postdoctoral Fellow at University College of Dublin under the direction of Prof. Robert D. O'Neill and Dr. John P. Lowry. His mainly research interest involves the development and application of neuroanalytical techniques to study neurodegenerative diseases.

Gaia Rocchitta has MSc in Chemistry. In 2004, she received her PhD in Neuroscience at Sassari University under the direction of Prof. M.S. Desole and Prof. E. Miele and the supervision of Mr. G. Esposito. Currently she is working as a Postdoctoral Fellow at University College of Dublin. Her main research interests involve development of Glutamate biosensors and their application for in vivo detection of Glutamate in rats in physiological and pathological conditions.

Gianfranco Bazzu is graduated with a MSc in Biology in 2004 at University of Sassari where is taking a Ph.D in Neuroscience at Department of Pharmacolgy. He is studying in vivo neurochemistry using microdialysis and voltammetry and he's developing biolectronic and biotelemetric devices.

Antonio Manca has achieved the MSc in Natural Sciences in 1999 and a BSc in Biotecnology in 2005. He is a PhD student in Neuroscience at University of Sassari where he is studying animal behavior in animal models of Parkinson's Disease.

Giulia Puggioni has a MSc in Biology (2002) and a BSc in Biotechnology (2005). She is PhD student at the Department of Pharmacology at University of Sassari where she is developing microsensors and 
biosensor applied to quantification of neurotransmitters in neurodegenerative diseases.

John P. Lowry received his BSc in Chemistry from University College Dublin (UCD) in 1988. He received his Ph.D in Bioelectroanalytical Chemistry from UCD under the direction of Prof. Robert D. O'Neill in 1992. Prior to his first academic appointment he was a Marie Curie Fellow at the University of Oxford where he worked in the University Laboratory of Physiology with Dr. Marianne Fillenz. He was appointed as a University Lecturer in Analytical Chemistry at the National University of Ireland, Maynooth (NUIM), in 1998. In 2004 he became a lecturer in Pharmacology at the Conway Institute UCD and returned to NUIM in 2006 to take up the Chair of Chemistry. His research interests are in the area of bioanalysis particularly in the development, characterisation and application of sensor and biosensor systems for in vivo neurochemical monitoring.

Robert D. O'Neill, PhD, is professor of Electrochemistry at UCD, Dublin, and a founding member of the Neuroanalytical Chemistry Laboratories (www.naclgroup.org). He received his BSc in Chemistry (1976) and PhD in Electrochemistry (1980) from UCD, and was awarded research fellowships in Oxford University for postdoctoral studies in physiology and neurochemistry (1980 - 1985). Professor O’Neill's research program focuses on design and application of microsensors and biosensors for electrochemical monitoring of brain signalling systems. 